\title{
Analysing the interactions of energy and climate policies in a broad policy 'optimality' framework: the Italian case study
}

Davide Antonioli, Simone Borghesi, Alessio D'Amato, Marianna Gilli, Massimiliano Mazzanti \& Francesco Nicolli

To cite this article: Davide Antonioli, Simone Borghesi, Alessio D'Amato, Marianna Gilli, Massimiliano Mazzanti \& Francesco Nicolli (2014) Analysing the interactions of energy and climate policies in a broad policy 'optimality' framework: the Italian case study, Journal of Integrative Environmental Sciences, 11:3-4, 205-224, DOI: 10.1080/1943815X.2014.962549

To link to this article: https://doi.org/10.1080/1943815X.2014.962549

Published online: 18 Nov 2014.

Submit your article to this journal $\sqsubset$

Џ Article views: 216

Q View related articles $\square$

View Crossmark data ¿

Citing articles: 3 View citing articles $\sqsubset$ 


\title{
Analysing the interactions of energy and climate policies in a broad policy 'optimality' framework: the Italian case study
}

\author{
Davide Antonioli $^{\mathrm{a}}$, Simone Borghesi ${ }^{\mathrm{b}}$, Alessio D’Amato ${ }^{\mathrm{c}}$, Marianna Gilli ${ }^{\mathrm{a}}$, \\ Massimiliano Mazzanti ${ }^{\mathrm{a} *}$ and Francesco Nicolli ${ }^{\mathrm{a}, \mathrm{d}}$ \\ ${ }^{a}$ University of Ferrara, Ferrara, Italy; ${ }^{b}$ University of Siena, Siena, Italy; ${ }^{c}$ University of Rome Tor \\ Vergata, Rome, Italy; ${ }^{d} I R C r E S-C N R$, Milan, Italy
}

(Received 4 April 2014; accepted 3 September 2014)

\begin{abstract}
The paper investigates the effectiveness and efficiency of energy-environmental policy interactions in Italy, adopting a broad optimality perspective that includes policy feasibility and dynamic efficiency. The analysis highlights that though some complementarity among different policies exists, climate policies have been often undermined by energy and renewables policy. Nevertheless, some complementarities among policy landscapes are found, as in the case of the Kyoto Fund (climate policy) and of the incentives and funding towards thermal energy, both acting as a complementary tool to cover non-EU-ETS sectors. Overall, renewables oriented policies bring about efficacy, but this often occurs at the expenses of their efficiency, thus generating a trade-off between these two components of optimality. Finally, incentives for renewables and energy efficiency investments give a mixed signal to improve innovation and to stimulate the green sector. In conclusion, notwithstanding efficacy is present in some cases, cost effectiveness and efficiency are far from being achieved.
\end{abstract}

Keywords: environmental policy; interactions; optimality; energy; carbon pricing

\section{Introduction}

The European Commission roadmap towards a low-carbon economy sets out ambitious targets in terms of emission reduction to be reached by 2050 . Socio-economic, technology and policy issues are relevant to set a green economy pathway (EEA 2013a, 2014), wherein climate change policy is of special relevance for the radical changes a low-carbon economy needs. The EU committed to reduce emissions by $80-95 \%$ with respect to the 1990 level in order to hold global warming below the threshold of the $2^{\circ} \mathrm{C}$ rise in temperature (COM/2011/0112). Similarly, the UN Intergovernmental Panel on Climate Change [IPCC] recommends a reduction by at least $50 \%$ by 2050 with respect to the 2000 levels, in order to limit the negative consequences of climate change (IPCC, 2007). A relevant role in this transition is played by the industrial sector, the emissions of which are prospected to increase by $74-91 \%$ by 2050 compared to 2007 , the current scenario being unchanged (Napp et al. 2014). To achieve this transformation, the existing mix of climate and energy policies needs to evolve significantly and more attention has to be paid, by both researchers and policy-makers, to optimality and to the interactions among different instruments. An optimal policy portfolio needs to be economically efficient,

*Corresponding author. Email: mzzmsm@unife.it 
environmentally effective and politically, legally and administratively feasible. Moreover, also the interactions across different instruments can play a crucial role, as these can reinforce each other, or on the contrary, inhibit reciprocally.

The objective of this work is to perform an initial 'stock-take' of the climate policy instruments for Italy, a big European country which accounts for about $10.7 \%$ of EU greenhouse gas (GHG) emissions, reduced by 5.8\% over 1990-2011 (EEA 2013a), but on a mixed pattern in the recent past if comparatively assessed (Figures 1 and 2). Italy is a peculiar case study among others, given it is a large - still industrial - country, which has based its historical environmental policy strongly on the 'energy side', with only recent

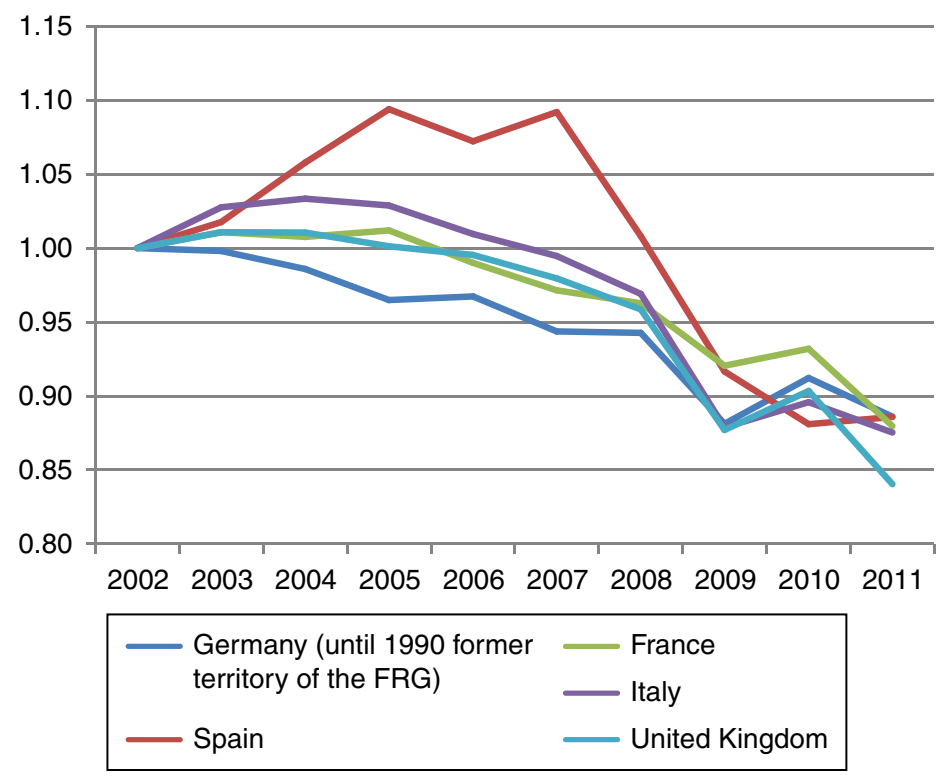

Figure 1. GHG trends $(2002=$ kgoe per 1000 EUR (kilograms of oil equivalent per one thousand euros); see http://epp.eurostat.ec.europa.eu/cache/ITY_SDDS/DE/tsdec360_esmsip.htm). Source: Authors' elaboration on Eurostat data (March 2014).

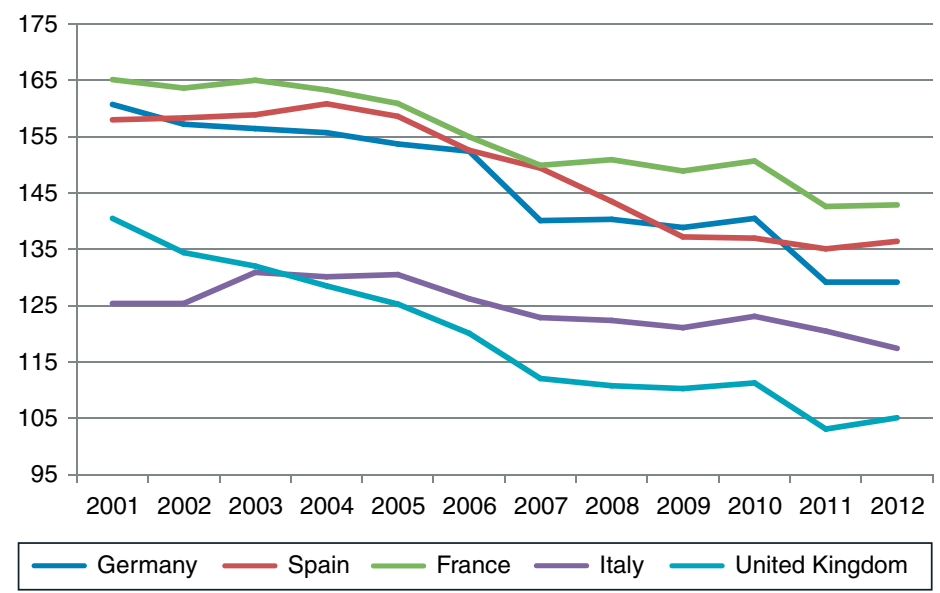

Figure 2. Energy intensity of GDP. Source: Authors' elaboration on Eurostat data (March 2014). 
(and possibly late) insertions of climate-related policy. Its carbon dioxide emissions performances are not excellent, though the country historically presents structural high energy efficiency (EE).

The climate change policy setting in Italy revolves around the European Union Emission Trading System (EU-ETS) as in many countries. The country policy action for reducing GHG is composed of other pillars, the most important of which is the set of policies on EE and renewables that was introduced over the last decade. The introduction of a carbon tax on non- ETS sectors has been discussed. It is worth to notice, as transversal policy scheme, the so-called Kyoto Fund that is in principle aimed at financing $\mathrm{CO}_{2}$ reduction investments through low interest rates. The fund is possibly fuelled by the ETS auction revenue. The list of instruments for Italy, along with their landscapes classification may be seen in Table 1. More specifically, this article evaluates instruments implemented at country level, and attempts to assess their individual 'optimality', based on the concept developed in Section 2. Detailed descriptions of interactions among instruments within each landscape are also provided. The categories and methods are based on best practice in instrument interaction assessment. We believe this analysis presents new and relevant results, which enrich the environmental policy debate from many perspectives. First, we provide an assessment of the complex mix of environmental and energy policy for a big European country like Italy; second, we propose a taxonomy to aggregate such wide array of policy instruments into a smaller set of policy landscapes; third, we move a first step towards a definition of optimality of these instruments referring to their economic

Table 1. List of selected instruments by policy landscape.

\begin{tabular}{|c|c|c|c|c|}
\hline \multirow[b]{2}{*}{ Policy instrument } & \multicolumn{4}{|c|}{ Policy landscapes } \\
\hline & $\begin{array}{l}\text { Carbon } \\
\text { pricing }\end{array}$ & $\begin{array}{c}\text { Energy } \\
\text { efficiency } \\
\text { and } \\
\text { energy } \\
\text { consumption }\end{array}$ & $\begin{array}{l}\text { Promotion } \\
\text { of renewable } \\
\text { sources of } \\
\text { energy }\end{array}$ & $\begin{array}{l}\text { Non- } \mathrm{CO}_{2} \\
\text { GHGs }\end{array}$ \\
\hline ETS & \llcorner & & & $\nu$ \\
\hline Kyoto Fund ${ }^{\mathrm{a}}$ & 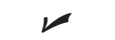 & $\mathscr{\nu}$ & $\nu$ & $\nu$ \\
\hline Energy efficiency-related tax incentive & & $\nu$ & & \\
\hline Energy performance certificate for buildings & & $\nu$ & & \\
\hline Incentives for the purchase of vehicles & & $\nu$ & & \\
\hline White certificates & & $\nu$ & & \\
\hline $\begin{array}{l}\text { Renewable energy for heating \& cooling } \\
\text { support scheme (Conto Termico) }\end{array}$ & & レ & $\nu$ & \\
\hline All inclusive tariff (tariffa omnicomprensiva) & & & 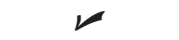 & \\
\hline Certificates of release for biofuels consumption & & & 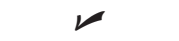 & \\
\hline $\begin{array}{l}\text { Feed-in tariff/premium (Conto Energia) } \\
\text { photovoltaic }\end{array}$ & & & $\nu$ & \\
\hline Green certificates & & & $\nu$ & \\
\hline $\begin{array}{l}\text { New feed-in premium for renewable } \\
\text { energy sources other than photovoltaic }\end{array}$ & & & $\nu$ & \\
\hline Regional objectives for renewable energy & & & 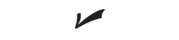 & \\
\hline Landfill tax & & & & 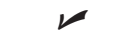 \\
\hline $\begin{array}{l}\text { Waste management tariffs (tariffa igiene } \\
\text { ambientale) and new TARES (since } \\
\text { January 2013) }\end{array}$ & & & & レ \\
\hline
\end{tabular}

${ }^{a}$ Though the fund is not properly a specific carbon pricing tool, it finances GHG abatement investments and is possibly fuelled in the future by ETS auction revenues. 
efficiency, environmental efficacy and political feasibility; lastly, we address the complex issue of interaction among the different instruments, which is fundamental in an overall assessment of a country policy mix.

The paper is organised as follows. Section 2 presents methodological issues; Section 3 presents the analysis of the different policy landscapes; Section 4 evaluates the overall instrument mix and Section 5 concludes.

\section{Methodology: setting the policy landscapes ${ }^{1}$}

From a methodological perspective, we gathered all the available information on the implemented energy and climate change policies in Italy (ending up with more than 100 policy instruments in environmental and energy realms somewhat connected to carbon dioxide reduction aims), and summarised them in the taxonomy proposed below (see also Table 1). Information on the different policies is mainly derived from the ministry of the environment website, and is integrated with the original legislator text of the bills. ${ }^{2}$

Policies are grouped in four policy landscapes ${ }^{3}$ :

(1) Carbon pricing: This includes policies that price $\mathrm{CO}_{2}$ emissions or otherwise change the relative prices of fuel use, depending on the carbon intensities of fuels. Apart from the obvious candidates (carbon taxes and emissions trading) this would include the reform or removal of fossil fuel subsidies.

(2) Energy efficiency and energy consumption: This includes measures targeted either at increasing the efficiency of the energy sector, including power generation/ combustion processes, transmission of energy (heat, electricity) and end-use efficiency, or at reducing energy consumption (demand-side management, energy saving, sufficiency).

(3) Promotion of renewable sources of energy: This includes policies aimed at increasing the share of energy from renewable sources (solar, wind, hydro, biomass, geothermal).

(4) Non-carbon dioxide GHGs: This covers policies geared at reducing non- $\mathrm{CO}_{2}$ GHG emissions, typically from sectors other than the energy sector. It may include methane emissions from landfills or animal husbandry, $\mathrm{N}_{2} \mathrm{O}$ emissions from agriculture or GHG emissions from chemical industries (SF6, NF3, HFC, etc.).

In order to create a feasible and manageable analysis, we reduced the high number of policies surveyed to 15 (Table 1). By using experts' opinions ${ }^{4}$ and explorative comparisons, we deleted instruments that shared strong similarities with others and were too marginal with respect to the overall framework (economically marginal, very sector specific, very regional specific) ${ }^{5}$

After the definition of the policy landscapes and the subset of tools, we address the 'optimality' of the different instruments according to the following three criteria. We refer in the text to previous academic literature and anecdotal evidence in order to assess the degree of optimality of the different instruments. Optimality is defined and assessed following a broad and extensive meaning, where efficiency, effectiveness and social feasibility are considered. ${ }^{6}$

(1) Environmental effectiveness: It reflects the capacity of the different policy instruments to achieve the expected results. 'Results' can be described as policy outputs (e.g. laws and regulations passed), policy outcomes (e.g. share of renewable energy or number of electric vehicles) or policy impacts (e.g. dangerous 
anthropogenic climate change avoided). The most important yardstick is whether the proposed policies can be expected to bring about the necessary emission reductions (in the order of $80 \%$ below 1990 levels by mid-century).

(2) Cost-effectiveness and efficiency: At what cost are the necessary emission reductions achieved, and does the instrument mix guarantee that they are met at least cost. This criterion is further explained in two sub-criteria:

- Static efficiency: Achieved when all emission sources are covered by the set of policy instruments, and when all emitters face an equivalent incentive to reduce emissions - be it through a carbon price or some other (dis-)incentive (Baumol and Oates 1988).

- Dynamic efficiency: Entails an efficient level of innovation and diffusion of low-carbon technologies in order to lower abatement costs in the future. In this way, dynamic efficiency is a means of minimising the total cost of achieving climate targets over a given time period (Del Rio and Bleda 2013). It links the dimension of carbon pricing to the dimensions of technology and behavioural change (Grubb 2014), three pillars of a dynamic oriented economic policy towards climate change target achievements.

(3) Feasibility: Describes the risk that the policy fails to be adopted and subsequently implemented as planned (outputs), and the risk that the instrument fails to deliver as expected (outcomes). ${ }^{7}$ This can be assessed at least in three dimensions ${ }^{8}$ :

- Social and political feasibility ${ }^{9}$ : Acceptance of policies by the public at large (in their function as voters or as consumers), and support for climate policy by policy-makers and stakeholders, who are willing to promote or to defend such initiatives.

- Legal feasibility: Compatibility and coherence of climate policy instruments with existing EU legislation, as well as national legislation.

- Administrative feasibility: Administrative burden for compliance and enforcement (including the monitoring, reporting and, if necessary, verification of emissions), covering both the transaction cost for regulated entities and the administrative effort required from government agencies to effectively implement an instrument and ensure compliance.

\section{Description and evaluation of policy landscapes in the light of the concept of optimality}

\subsection{Carbon pricing}

Carbon pricing has been applied in Italy almost exclusively through the implementation of the EU ETS and, to a lesser extent, through the complementary action of the Kyoto Fund mechanism.

The implementation of the EU-ETS largely reflects an economic efficiency criterion. It is well known that cap-and-trade systems theoretically allow achieving the necessary emission reductions at least cost. From an empirical investigation conducted on the EU-ETS Italian sectors (Borghesi et al. 2012), however, the EU-ETS seems to have satisfied mainly a static rather than a dynamic efficiency criterion. In fact, in the first phase of the EU-ETS, its implementation has had a limited impact on the innovation and diffusion of low-carbon technologies. This applies particularly to some specific EU-ETS sectors (i.e. cement) that seem to have mainly followed a 'wait and see' policy so far: most of the firms in these sectors tended to keep their quotas and preferred not to sell them in front of future uncertainties on targets, mechanisms and prices. In any case, difficulties in data dissemination have been 
important in hindering a proper evaluation of both the static and dynamic efficiencies of this instrument in Italy, while posing serious doubts on the transparency of its implementation. Such doubts seem to be further supported by some recent scandals (like the one involving the 'Italcementi', one of the major Italian cement companies) regarding installations that were not duly reported by some firms under the EU-ETS.

The relatively small ecological innovations induced by the EU-ETS so far also casts doubts on the environmental effectiveness of this instrument in Italy, as well as on its dynamic efficiency. The observed reduction of Italian carbon dioxide emissions in the last few years can be ascribed to the ongoing deep economic crisis rather than to a drastic shift to renewable energy sources (RES) and/or to a new technological paradigm adopted in the country. If one looks at Italian environmental performance, in fact, it can be easily noticed (cf. EEA 2010) that when the crisis began in 2007, the emission level was well above the intermediate target needed to achieve the final Kyoto target established for our country ( $-6.5 \%$ by $2008-2012$ with respect to the 1990 levels).

Finally, a proper evaluation of the EU-ETS in Italy cannot disregard a few implementation problems in terms of its policy feasibility as emerged in the first two phases. While some of these problems are common to most EU countries, others seem to be linked to specific features of the Italian economic and institutional framework. First, the Italian National Allocation Plan allocated an excessively high number of emission permits that were inconsistent with the Kyoto target. This problem, that occurred both during the first and the second trading phase, was mainly due to political pressures on the government from interest groups who wanted to receive as many permits as possible. Although the centralisation of the allocation system has eliminated this problem for the third phase, great effort has been placed in Italy on lobbying actions also in the new EUETS phase to be included in the 'free auction' share of firms. The Italian Industrial Association (Confindustria) has often criticised in its official newspaper (Il Sole24ore) the planned shift from the grandfathering to the auctioning system, due to the expected increase in firms' costs and the related risk of carbon leakage. On the other hand, it can be argued that the free allocation of permits according to a grandfathering criterion may have generated windfall profits for a few large firms in key sectors (e.g. energy companies), which may further reduce the relatively small competition level characterising these sectors in Italy. Though this problem is common to other EU member countries (cf. Ellerman and Joskow 2008; Pearson 2010), the high number of small and medium enterprises (SMEs) characterising the Italian economic system makes this issue even more relevant in Italy. While the implementation of an auctioning system could certainly reduce windfall profits and increase the government revenues to be used for environmental purposes, it would not preserve/increase per se the competition in the EU-ETS sectors, unless it is properly designed. In this regard, recall the past Italian experience in other contexts, such as the auctioning of the Universal Mobile Telecommunications System (UMTS) licences. In that case, limited market competition (and possibly collusion among participating firms) caused the auction price and the government revenues to be much lower than expected. ${ }^{10}$

The widespread presence of SMEs in the Italian economic context makes the Kyoto Fund mechanism particularly attractive in our country. The Kyoto Fund, established by the Financial Law in 2007, was conceived to finance the GHG emissions reduction intervention requested by the Kyoto Protocol.

The implementation of the Kyoto Fund, which was expected to take place in November 2008, was unfortunately delayed up to March 2012, when the first €200 millions of the overall €600-million fund were set free to start the programme. In the first 
phase, most of the fund (€130 million) was earmarked to final uses (e.g. thermal insulation, cogeneration heating systems, geothermal systems); €35 millions were committed to support widespread micro-cogeneration systems, €10 millions to renewables (wind and hydro power, solar thermal, installations of photovoltaic panels, etc.) and $€ 35$ millions for other activities (e.g. replace electric engines, reduce $\mathrm{N}_{2} \mathrm{O}$, support $\mathrm{R} \& \mathrm{D}$ on renewables, hydrogen and fuel cell).

The impressive number of submissions immediately received (605 requests in the first two hours and the exhaustion of almost all financial resources destined to the renewables in about three days) signals the difficulties that many SMEs often encounter in Italy accessing the financial support to perform eco-innovations. Moreover, it also suggests that the bureaucratic obstacles that have postponed the beginning of the programme by about five years have probably resulted in a serious slow down of the Italian eco-innovations over a crucial period that encompassed the ongoing economic crisis. This may have further enlarged the technological gap that Italy seems to suffer with respect to other countries in terms of eco-innovations, with an innovation rate that is currently much lower than that of Germany and Scandinavian countries (cf. Borghesi et al. 2012).

Although the Kyoto Fund can be seen primarily as a financial support mechanism to the other policy landscapes (especially renewables and EE), it is strictly linked to the carbon pricing policy landscape defined by the EU-ETS, as part of the entries obtained from the EU-ETS auction (first figures to be released by member states in October 2014) are going to be bound to the Kyoto Fund. On the other hand, by supporting RES, EE and $\mathrm{N}_{2} \mathrm{O}$ abatement, the Kyoto Fund helps the firms meeting their EU-ETS requirements, thus creating a strict interdependency between these two measures and the related policy landscapes.

Unfortunately, the lack of alternative carbon pricing policies beyond the EU-ETS in Italy prevents us from identifying further possible interactions within this policy landscape. Summing up, the only true carbon pricing policy introduced in Italy so far has been implemented 'from outside' (i.e. following the EU Directive) with some application difficulties beyond those emerged at the overall EU level, and there is still a significant gap in our country that remains to be filled in carbon pricing policies in the future.

\subsection{Energy efficiency and energy consumption}

This landscape is the most substantial together with the renewable oriented landscape, if they are compared to carbon pricing, in terms of scope and number of instruments. This shows up that besides the EU-ETS, the Italian system is biased towards energy policies. This statement is noteworthy, since the need to analyse interactions within and among policy landscapes derives from the lack of specific climate policies and fully integrated climate-energy strategies. As example among others, national energy and environmental taxation amounts to $€ 40.7$ billions in 2010 , of which only $€ 491$ millions pertain to environmental and resource taxes and $€ 31.2$ billions are energy taxes (Istat 2012). This is possibly true over other EU countries as well, but it is more pronounced in Italy.

Among the instruments that were initially selected, we finally drew out six tools, some of which have been refined through time, while others are brand new:

(1) the Kyoto Fund;

(2) white certificates;

(3) energy performance certificate for building;

(4) EE-related tax incentives; 
(5) incentives to purchase cleaner vehicles;

(6) Renewable energy for heating \& cooling support scheme (Conto Termico). ${ }^{11}$

Some have economy-wide effects; some are related to housing, consumers and buildings (e.g. 6). A key distinction in that respect is whether they support efficiency for electricity or thermal sources.

The identified package is partially composed of tools that support EE through funding investment projects $(1,4,5)$ and tools that operate through markets (e.g. 2). Tools based on proper 'pricing' rationale as such are absent, if we exclude the substantial, but far too general, energy taxation, which we decided to exclude from the specific set of tools.

Another general consideration is that uncertainty covers the future of subsidies and incentives which are funded by yearly financial bills, as well as renewable oriented incentives. This is shared with other countries, given the current stagnation of the cycle and public finance issues. The weight of Italian debt adds constraints to expectations on the side of tools funded through the general fiscal pool.

The key and oldest instrument are the white certificates that were introduced in 2004. They provide the possibility to generate resellable allowances when EE investments are implemented. The measure unit is $€ 100$ per tonne of equivalent oil, the electricity consumption of a family in a year. Big players compulsorily join the system, while other agents voluntarily enter. Efficiency is related to electricity, natural gas and fuels. Quota exchanges are on a bilateral basis or through institutional authorities. The market is monitored by the Authority for Electricity, Gas and Water (AEEG). National authorities determine the energy saving targets. Players can benefit from selling certificates in excess or for being compliant with the targets. Certificates originate both at the level of production and consumption through the selling of more efficient tools to consumers.

As far as economic efficiency is concerned, we can state that the key instrument of the bundle (white certificates) possesses efficiency rationale, insofar as it is framed in a tradable system and the reward is somewhat proportional to the value of the energy saving project. This is less true for tax deductions oriented at EE, the relevance of which is massively important. Those measures have been largely used to achieve development and energy goals, as well as growth-oriented goals related to the important construction sector in Italy. We nevertheless signal two interactions that might have undermined the white certificates and tax deductions performance through partial crowding out; first, energy saving-oriented tax deductions might crowd out more efficient 'certificates' markets through overlapping: enjoying high tax deductions or incentives, e.g. for a building requalification and for the purchasing of cleaner vehicles, respectively, may 'displace' a potentially more efficient use of white certificates, which could be targeted to the same objectives (building requalification and diffusion of cleaner vehicles). Second, tax deductions themselves might be crowded out by 'general' (non-energy-oriented) building renewal tax incentives that have been normally in place over the same periods of time. The various interactions affect efficiency, mostly through negative effects, and efficacy.

The last decade and the new incentive systems and markets introduced in 2012 further changed the picture. Interactions are dealt with by the legislator through the avoidance of cumulativeness of different incentives. This partially mitigates crowding out effects and in some cases preserves efficiency.

Overall, efficiency contents, even in a broad sense, are mildly present. Proper pricing mechanisms are limited. Energy taxation is not aimed at achieving GHG reduction and EE, and 'taxation recycling' systems do not exist (e.g. using revenue to fund innovation or labour tax cuts). 
We also observe that strong uncertainty exists in the Italian system in relation to the combination of different tax incentives and funding opportunities, due to volatile expectations that can generate distortions in investments over time (peaks and bumps, waiting to see behaviour, etc.) and that are a key element in the analysis of the EE policy package.

An additional possible drawback of using different, cumulated and overlapping instruments is that this can hinder their evaluation: each instrument should be tested with a careful cost-benefit analysis. Its results could be used to establish a hierarchy among different instruments in terms of economic efficiency, social desirability and environmental impact.

As far as effectiveness is concerned, we might claim that the achievement of EE is not reached in the medium-long run, given that the macro figure (Figures 1 and 2) shows that the country has stabilised its (high) EE. The gap with other countries has diminished over time, with some (the UK, Denmark) moving ahead of Italy. The motivations have to be found at a more meso/micro-scale by looking at specific sectors dynamics along innovation and structural change directions (Gilli et al. 2013; Marin and Mazzanti 2013).

The overall package probably lacks ambitiousness and integration, namely research of complementarity among instruments and landscapes. Clearer pricing-based rationales would probably help to restructure relative prices within the economy. In a nutshell, a carbon-energy tax redefining prices and incentives could be more effective as key policy pillar compared to a jungle of EE and renewable oriented funding tools that interact in various ways, with complementarity but also relevant trade-offs showing up.

Regarding policy feasibility, we should stress that transaction costs are present due to (1) the envisaged and commented interactions and (2) the various ministries and agencies involved in EE policies and monitoring actions. Moreover, in the specific case of white certificates, they are even more likely to incur in transaction costs (Mundaca 2007) due to the fulfilment of administrative requirements, measurement and verification of activities, search for information and other more. For the UK case study, Mundaca (2007) findings show that transaction costs are around $10 \%$ of the investment costs for the lighting segment and $30 \%$ for the insulation segment, but still the energy savings gained more than compensate the transaction costs, yielding a positive net societal benefit.

Distributive issues are crucial as in all environmental policy schemes. In this landscape and in the renewable energy landscape, the way taxes and/or tariffs fund tax deductions and subsidies is a crucial issue.

Competitiveness is a major factor as well. Most tax incentives for energy saving investments, and the broader tax deductions for renewing buildings are within the umbrella of actions aimed at increasing GDP. This depends upon the huge role of the construction sector in Italy. Whether those schemes should present 'economic development' as main aim is questionable and to be assessed on economic grounds. In fact, there may exist sectors presenting higher value added per employee to eventually support. Again a more radical and central scheme of energy/environmental taxation may function as a lever for new competitiveness sources within the transition towards a greener economy.

\subsection{Promotion of renewable sources of energy}

In compliance with several EU laws and Directives devoted to the promotion of RES (Directive 2009/28/CE among others) and coherently with the 20-20-20 obligations, renewable energy has been subject to substantial intervention, mainly through the use of 
subsidies in the form of feed in tariffs or premiums, green markets in the form of green certificates and tax exemptions or deductions. Heat production from renewables has benefited of tax rebates and, more recently, of a system not far from that related to renewable electricity: the so-called Conto Termico (see above). Finally, biofuel use in transport is promoted through an obligation to mix 'traditional' fuels with a percentage of biofuels.

Under an economic efficiency point of view, two levels of considerations are needed:

- The overlapping with other instruments and policy realms (mainly EE and carbon pricing) with linked objectives (EU-ETS, among others) might have led to efficiency losses. The issue of overlapping regulation is discussed in detail in Section 4.

- The link between the costs of feed-in tariffs and other subsidies and the benefits from the reduction in damages due to fossil fuels-related emissions is another crucial variable to be considered in assessing the efficiency of policy design and, specifically, of the renewable electricity subsidies' systems. So, for example, the average subsidy from Conto Energia to Photovoltaic (PV) energy was, in 2011, equal to $€ 0.37$ per $\mathrm{kWh}^{12}$; other examples: the price at which green certificates not sold in the market were bought back by Gestore del Sistema Elettrico (GSE) in 2011 was €82.12 per MWh. PV electricity produced through plants with nominal power up to $1 \mathrm{MW}$ and sold through 'Ritiro Dedicato' was granted in the same year (below certain thresholds) a 'price' between €76.2 and 103.4 per MWh. Though no easy way of aggregating these (and other relevant) cost figures exists, such costs should be compared with the estimates for external costs related to fossil fuel combustion in the production of electricity. An example in this respect is given by the estimates of the average EU external costs for electricity generation technologies reported by the European Environment Agency (EEA), ${ }^{13}$ according to which the average EU external costs from fossil fuel electricity could reach, in 2005 , over $€ 0.25$ per $\mathrm{kWh}$. Unfortunately there is no way, at the moment, to compare easily the costs and the benefits side, so an additional up-to-date research is needed in this field.

Hints on the dynamic efficiency of policies related to renewable energy can be obtained from the 2013 OECD Environmental Performance Review on Italy, namely from the patenting activities linked to renewable and non-fossil energy technologies. Indeed, from year 2000, the number of such patents in Italy has increased at a fast pace. Also, in 20072009 renewable energy-related patents accounted for more than one-third of all patents linked to environment- and climate-related technologies. Nonetheless, significant improvements are still needed, as testified by the small percentage $(2.5 \%)$ of renewable and non-fossil fuel energy Italian inventions as compared to OECD as a whole and by the poor performance of other policy instruments (e.g. EU-ETS, see above) in terms of impact on overall eco-innovation performance (Borghesi et al. 2012).

Focusing on the feasibility of policies, the involvement of several levels of government, with potentially conflicting objectives, is one of the most important shortcomings when focusing on renewable energy policies. Two examples can be reported in this respect. First of all, the significant incentives (though decreasing over time) have led to a huge increase in renewable energies. This has created significant bottlenecks during the decision processes of local authorities that were in charge of providing the needed permits, especially before a national guidance for such permits was issued (Ministry decree 10 September 2010). Second, the effectiveness of RES-related subsidies has been to some extent affected by fiscal treatment of the related revenues and/or costs: 
for example, a (temporary) preferential treatment for PV plants built in linkage with agricultural activities has led to a boost in these plants installations, implying a potential crowding out of other kinds of plants and also affecting agricultural activities. Another important point is related to the potential impact of regulatory uncertainty. Indeed, the attitude of the regulator(s) seems to have been, at least in some moments, that of 'reacting' to existing evidence rather than to plan a long-run strategy. A possible hint in this direction is given by the passage from the Terzo to the Quarto Conto Energia.

Notwithstanding these problems and decreasing subsidies over time (e.g. the average PV-related subsidy decreased from $€ 0.435$ per $\mathrm{kWh}$ in 2009 to $€ 0.37$ per $\mathrm{kWh}$ in 2011), ${ }^{14}$ the subsidies regimes have been effective in boosting the installation of renewable energy plants, although additional progress is needed. More specifically, the 2012 statistical report for PV electricity (from GSE) shows how PV electricity production in the same year has reached $18.862 \mathrm{GWh}$, with an increase of $75 \%$ with respect to 2011 and 485 -fold since 2007. Similar, though less pronounced, trends can be found in other sectors, such as wind and bioenergy.

Environmental effectiveness has shown an 'average' performance for Italy so far. Indeed, the EEA ${ }^{15}$ illustrates that from 1990 to 2009 the share of renewable energy in total gross inland energy consumption increased from $4.2 \%$ to $9.5 \%$, slightly above the $9 \%$ share in 2009 for the $\mathrm{EU}_{27}$. Yet, Italy has been judged (by the EEA) 'well on track' to meet its 2020 RES targets: indeed, in 2011 the share of renewable energy in gross final energy consumption was $11.5 \%$, therefore larger than its indicative target trajectory under the Renewable Energy Directive (EEA 2013b).

\subsection{Non-carbon dioxide greenhouse gases}

Within the overall set of instruments, the instruments we focus on are the Italian landfill tax and the waste tariff (known as TIA, introduced in $1999,{ }^{16}$ currently under reform and substituted with the new TARES - which acronym stands for the italian 'municipal tribute for waste and services'- by the Bill 214 of 22 December 2011 no. 214). Though it is not based on proper evaluation of environmental external costs, the former has changed the relative price between waste management and disposal. The TIA provides some economic incentives and structurally funds the activity of separated collection of waste which grounds recycling and disposal forms as well. The other possible relevant tool that is included in the extended set of instruments is the pesticide tax, which changes the relative price between organic and non-organic agricultural systems and products. Overall speaking, the landfill tax is the key tool in this landscape.

The landfill tax helps reducing GHG through its impact on landfill diversion (EEA 2009; ETC/SCP 2013).

The landscape is relatively more relevant in Italy with respect to other countries, given the share of agriculture-based GHG emissions (30\% in 2009 compared to $26.7 \%$ in the $\mathrm{EU}_{27}$ ) and the still important share of waste being landfilled, notwithstanding important achievements over the past, also attributable to the landfill tax (D'Amato et al. 2013 for various empirical evidence on Italy). On that basis, significant reductions of $\mathrm{CH}_{4}$ might be obtained by full compliance with the Landfill Directive and the introduction of complementary management and disposal-oriented tools. The increase of landfill tax levels and diffusion is a potential key pathway. Policies help reducing waste being landfilled: the EU witnessed two significant structural breaks in the series: 2001 for $\mathrm{EU}_{27}-$ with MSW landfilled per capita decreasing from $300 \mathrm{~kg}$ per head in 1995 to $200 \mathrm{~kg}$ per

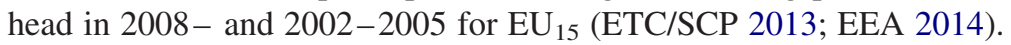


Within the aforementioned lack of environmental taxation, landfill tax and pesticide tax represent key examples of 'environmental taxation' in the country.

The landfill tax is the most relevant environmental tax in Italy. Introduced in 1996, it has not been regularly adjusted by regions since then (ETC/SCP 2012). Its revenue, due to the lack of regular adjustments, at least to inflation, and to the decrease in landfilled waste, has shrunk from $€ 315$ millions in 1996, out of $€ 434$ millions of all environmental and resource taxes, to $€ 189$ millions out of $€ 490$ millions in 2011 (Nicolli and Mazzanti 2013).

Along similar lines, the waste management tariff TIA was introduced by a 1999 Bill which delegated its application to municipalities, and thus generated a non-uniform implementation of the tariff. We highlight the general consideration that in 'federal' countries such as Italy the delegation of competencies to regions and beyond is associated to the benefits and costs of decentralisation of public good provision (Mazzanti and Zoboli 2013).

Both the landfill tax and the waste tariffs obey to environmental federalism, namely they are effectively implemented at regional and provincial level. Climate policies obey to more centralised principle though it might happen that EE targets are delegated to regions, especially if they pertain to specific sectors.

From the point of view of efficiency, none of the identified tools refers to efficiency as primary aim. The main rationale is to target a defined option (e.g. separate collection targets). The landfill tax should/could then fund sustainability investments, covering waste management fixed and variable costs. The TIA/TARES actually contains the possibility to abate the price paid through the application of composting (waste reduction).

Thus, they introduced a new economic rationale (e.g. the TIA turned over a general waste tax completely unrelated from waste systems feature and people's behaviour), but related to effectiveness (not cost effectiveness) at a general level.

From the point of view of environmental effectiveness, we might affirm that they separately and jointly contributed to increasing the performance of the system, and then reducing GHG emissions (D’Amato et al. 2013; Mazzanti et al. 2011) through landfill diversion and support for recycling.

Finally, policy feasibility issues are critical with respect to the (1) non-homogeneous diffusion of the two tolls over the territory, that might generate drawbacks in terms of average national achievements (Mazzanti and Montini 2014) and (2) lack of adjustments of the landfill tax due to typical inertia and una tantum implementation. Distributional impacts and competitiveness are probably minor issues in this case, even if more homogeneous, more integrated use of the instruments and an increase of landfill taxes might spur waste-related technologies as well, a source of double economicenvironmental gain (Nicolli and Mazzanti 2013).

\section{An evaluation of the overall instrument mix}

The overall instrument mix is the result of an historical process that has progressively shifted its emphasis from command and control tools to market-based instruments such as tradable schemes and taxes. The possible implementation of a carbon energy tax, briefly introduced at the end of the 1990s and eliminated shortly afterwards, does not seem to turn up in the political agenda today. Increasing attention has been devoted instead to the potential of trading instruments (e.g. white and green certificates and the ETS).

As it emerged from previous sections, some key policy instruments can be identified in the context of the Italian environmental strategy; those are probably white and green certificates, the EU-ETS, the large use of tax incentives to increase EE and the incentives to RES. 
Several cases of policy overlapping can be identified, both within and across policy landscapes.

As for the 'within landscape' cases, maybe the most visible is the one potentially arising between the national subsidies to electricity generation from RES (e.g. the socalled 'Conto energia' for PV electricity, or 'Tariffa omnicomprensiva' for other forms of electricity production) and the green certificates (to the extent they induce an increase of RES electricity, such as wind power or electricity generation from biomass). The recent evolution of the RES-related legislation is, however, phasing out the possibility to obtain green certificates, and this is likely to proceed in the direction of removing the possible overlapping.

A second, equally important, potential source of crowding out is linked to the fiscal rebates to improve the EE of buildings and for equipment refurbishing, that may have crowded-out white certificates. This issue has been suggested as potentially relevant in Section 3, when discussing about EE-related policies.

More significant potential cases of overlapping can be found concerning different policy realms and objectives. Among the main sources of such interactions, a significant role is played by the linkages between national policies and the EU-ETS equilibrium price. In general, if a national policy overlaps with the EU-ETS, then the environmental effectiveness and economic efficiency of the instruments mix might be affected.

More specifically, the promotion of RES and EE can possibly clash with the carbon pricing policies, as a significant amount of literature seems to suggest (Sorrell et al. 2009; Kolev and Riess 2009; Borghesi 2011; Convery et al. 2014). In particular, RES and EE policies contribute to reduce emissions if they are applied to sectors not covered by the ETS scheme, but may fail to do so if applied to the ETS sectors. In fact, without adjustments in the emissions cap, supporting these policies in the ETS sectors may end up with simply decreasing the demand of the emission permits, and thus their price, without generating additional emissions cut (cf. Thema et al. 2013, and the literature cited therein). This issue has been recognised also by the European Commission (EC) which pointed out the possible downward pressure of the Energy Efficiency Directive on carbon prices (EC 2011a, 2011b). ${ }^{17}$ If this is the case, RES and EE policies set forth in the ETS sectors could be seen as a substitute rather than as a complement to the ETS. This problem, that has been extensively examined for specific countries (e.g. Fridolfsson and Tangerås 2012, for Sweden and DIW 2012, for Germany), applies also to the Italian case, in particular to national subsidies or incentives to electric RES generation (conto energia, tariffa omnicomprensiva, etc.) and the green certificates.

Another potentially relevant case of interactions is expected to arise also between EE and renewable energy policies. Indeed, the promotion of RES in the heating sector can be expected to overlap with EE incentives, as they both cover mainly the residential sector.

An important caveat applies here: albeit several theoretical and empirical analyses seem to suggest that a significant loss in efficiency can be linked to the overlapping of instruments, there are also some possible justifications, based on the presence of positive complementarity among instruments. An important contribution in this respect is by Lehmann and Gawel (2013), who focus on the linkages between the EU-ETS and renewable electricity support schemes developed in EU countries and provide a very good survey of the related literature, albeit leaving the opportunity of a deployment of support schemes in addition to the EU-ETS as an open question. For our purposes, the authors identify several possible rationales for adopting overlapping regulation; these are mostly linked to technology development and adoption (motivated by market failures and by the path dependency and lock in phenomena that affect involved sectors) and to additional 
benefits related to renewable energy deployment (e.g. in terms of energy security improvements). ${ }^{18}$

Also relevant for the analysis of potential justifications of overlapping policy instruments is the paper by Del Rio (2010), who focuses on the potential links between renewable energy support schemes and EE measures, and underlines how such interactions can be expected to have limited consequences, mostly due to the different scopes and absence of direct interaction; on the other hand, the same author underlines that a crucial role is played by the specific policy design.

With all these caveats in mind, we anyway deem the overlapping across instruments as a possible explanation of the critical aspects of the energy and environmental policy mix in terms of economic efficiency, environmental efficacy and policy feasibility.

Overlapping instruments, in fact, can generate some systemic inefficiencies increasing the overall costs for achieving the 2020 targets. In this regard, since the electricity sector is already subject to the ETS, it would be desirable to extend energy saving measures from the electric and ETS sectors to the non-ETS sectors. This would enhance the systemic effectiveness of the related market-based instruments (IEA 2011). In general, differently from other countries (e.g. France), more than $70 \%$ of the EE measures have favoured a reduction of carbon emissions in sectors (such as the industry and power generation) already covered by the ETS, while only less than $30 \%$ of the energy saving has been achieved in the household, tertiary service and public administration thermal energy consumption. This has provoked a limited reduction of carbon emissions in the non-ETS sectors, where governments are financially liable for the compliance with the related target. In this regard, it should be pointed out that while Italian emissions in EU-ETS sectors have been systematically lower than the assigned cap, generating a surplus of allowances that private sector can sell in the emissions trading market, non-ETS emissions have been higher than the related target (Clò 2012), increasing public expenditure to purchase the required international credits needed to comply with the Kyoto target.

Beyond the economic inefficiency deriving from the lack of coordination among energy and climate market-based instruments, the current policy mix has had a limited environmental efficacy so far. The reduction of GHG with respect to the 1990 levels in Italy has been very low; most of the abatement has occurred after 2008 when the sharp fall in the production levels has drastically decreased also the corresponding emission level. While the Italian GHG reduction has been basically in line with other European countries (see Figure 1), the reduction of energy intensity per unit of GDP has been remarkably low even in comparative terms (see Figure 2). This caused Italy to lose much of the initial advantage it used to have in terms of EE with respect to Spain, Germany and France, and to be overcome by the UK in the ranking of the most energy efficient EU countries.

Finally, several problems remain to be solved also in terms of the policy feasibility of the current instrument mix. As pointed out above (see Section 3), the transparency on the actual functioning of some of the adopted measures seems rather limited. The same applies to the innovation impact of such measures. As shown by Pontoglio (2010) and Borghesi et al. (2012), for instance, the ETS has had a limited effect on eco-innovation in Italy in the early phases of its implementation, thus confirming similar results obtained by several studies conducted on other EU countries (e.g. Aghion et al. 2009; Hoffmann, 2007; Rogge et al. 2011; Schmidt et al. 2012). Moreover, the number of agencies and institutions being involved (the Ministry of the Environment, the Ministry of Finance, technical agencies, the energy regulator and other entities) appears to be too high and the overlapping of their respective tasks too large at the moment, which generates credibility and coordination problems. 
The unclear overlapping of different instruments and monitoring institutions and the lack of an economy-wide instrument are, in our opinion, the key problems to be faced in the future. Moreover, a remarkable feature of the Italian system is the lack of any carbon pricing policy. Although a carbon price obviously cannot overcome all existing barriers to the introduction of low-carbon technologies, the ETS has shown to be particularly weak in promoting new environment-friendly technologies due to the high volatility and the sharp decline of the carbon price on the ETS market. For this reason, one may wonder whether the introduction of a sufficiently high carbon tax might perform better in terms of overall optimality than the ETS, currently coupled with the many (partially conflicting) measures adopted so far. Though a carbon tax is a less flexible instrument than the ETS, it might provide a more reliable price signal to the economic agents, not affected by the desirable progressive increase of RES and EE.

Unfortunately, the problems described above do not seem to play a major role in the political debate, and few initiatives have been taken so far to face and overcome them. In particular, while Italy had historically a prominent role in the discussion on the carbon tax (originally proposed in 1991 by the former European Environment Commissioner, Carlo Ripa di Meana), little/no attention has been devoted to its possible implementation as an alternative to overcome the shortcomings of the existing measures. More generally, neither the overlapping issue nor the optimality of the environmental policies has been the object of any discussion in the political forum in recent years.

A final note is deserved for the Kyoto Fund, which somehow crosses the diverse policy landscapes and is therefore expected to help the effectiveness of policies aimed at boosting renewable energy and EE, although to a limited extent, due to delays in implementation as well as to the limited amount of available resources so far. Also, linkages with the carbon pricing policy landscape are evident, due to the commitment to direct (at least part of) the EU-ETS-related revenues accruing to the public administration to the Kyoto Fund.

\section{Conclusions}

Besides the EU-ETS, the Italian policy package on climate change is biased towards energy policies. Italy has never presented a key carbon (pricing) policy. Environmental taxes - net of energy taxation - represent a negligible $0.03 \%$ of GDP (thus currently less than $€ 1$ billion, source Istat 2012), resource and waste taxes being the largest share of this amount. Energy taxes are historically high, but mainly driven by a revenue-raising principle rather than by environmental externality considerations. It is in addition not clear if EE improvements are an objective per se or also a strategy to reduce GHG and improve the economy's resilience to oil price shocks.

Overall, the policy package has so far privileged technology - broadly defined specific pathways rather than market-based pathways.

Climate change targets as well as EE and RES goals are pursued by a policy package composed of different policy landscapes, wherein major and minor instruments are implemented.

Some key interactions are found within policy landscapes: for example, a key issue is the potential crowding out of energy saving markets based on certificates determined by the overlapping with tax incentives for building/housing that present clear 'economic' aims.

Main relevant interactions are emerging also among policy landscapes. Those 'wrong interactions' may deliver drawbacks in terms of crowding out effects that undermine the efficiency of any single instruments. A key interaction lies in the fact that linking the EUETS functioning to other schemes may have negatively affected the carbon price effect 
driven by the EU-ETS, possibly amplifying the impact of the excess supply of allowances due to the crisis. Some positive complementarity is nevertheless highlighted, regarding the carbon pricing and non- $\mathrm{CO}_{2}$ landscapes. There is, for example, a strong potential with respect to emission reduction from landfill diversion. The 'Kyoto Fund' can in addition act as a complementary tool to cover non-EU-ETS sectors, in relation to all landscapes, given its intrinsic flexibility as a lever of specific technology and behavioural change actions. The EU-ETS is finally complement to incentives and funding towards thermal energy savings not covered by the EU-ETS itself.

Overall, we might say that sector-specific actions prevail over economy-wide actions (e.g. labour tax cuts and/or innovation funding through environmental taxes). This 'fragmented' approach is not helped by the very decentralised nature of the Italian state, which delegates to regions many environmental policy issues. This might generate 'macro-economic' deficiencies as well when we extend environmental policy to other realms: competitiveness and innovation objectives are not fully consistent with the renewable policies portfolio. These renewables oriented policies bring about efficacy, but this often occurs at the expense of their efficiency, thus generating a trade-off between these two components of optimality. Incentives remuneration of renewables and also EE policies give a mixed signal to improve innovation and to stimulate the green sector.

It would be probably better to provide a clear and durable price signal using green taxation on the basis of 'double dividends' rationales. The proper revenue recycling of energy and ecological taxes, as well as of EU-ETS auction revenues, would be able to enhance coherence between carbon pricing and technology-specific and/or behaviouraldriven pathways. Feasibility is enhanced by recycling revenues of green taxes back to industry and households to support specific technologies and behavioural change, including information and education. This may introduce some efficiency costs. ${ }^{19}$ For this purpose, it would be desirable to decide whether cutting labour taxes is better than funding some (eco)innovation and $\mathrm{R} \& \mathrm{D}$ taking the joint economic-environmental viewpoint properly into account.

\section{Acknowledgments}

This paper is based on work carried out in the CECILIA2050 research project, funded by the European Union under the 7th Framework Programme for Research (grant agreement $n^{\circ} 308680$, www.cecilia2050.eu). It has benefited considerably from discussions with numerous partners in the CECILIA2050 research consortium, including Paul Drummond. We would further like to thank two anonymous reviewers. The usual disclaimer applies.

\section{Notes}

1. Methodology is developed within the FP7 project CECILIA2050 (www.cecilia2050.eu).

2. Available at the website www.normattiva.it.

3. This means that the initial set of policies was simplified to a manageable set of instruments on the basis of which to analyse trade-offs and complementarities. Interviews with experts (from Università Statale of Milan, National Bank of Italy, Rome, ENEA, Rome, LUISS University, Rome, University of Rome Tor Vergata, Ministry of the Environment, Rome and OECD, Paris) were used to simplify the set of tools as shown in Table 1. Experts were also interviewed to provide comments on the interlinkages among policies. The overall investigation outcome is thus a meta-analysis of authors' knowledge about case studies and literature and complement experts' opinions and knowledge.

4. An alternative option to ex ante and ex post 'modelling techniques' is to gather experts' opinions on future uncertain events (ex ante) or to assess complex ex post dynamics (Nordhaus 
1994; Morgan and Keith 1995; Arnell et al. 2005; Mazzanti and Zoboli 2006; Zubaryeva et al. 2012; Varho and Tapio 2013).

5. The full set of instruments is available upon request.

6. Even in the mainstream realm there are seminal pieces of work that create bridges between approaches and help addressing the 'optimality conundrum'. As example, the Baumol and Oates (1988) 'standard and charges approach', that approximates Pigouvian outcomes without requiring strict neoclassic assumptions: 'The charges (or prices) would be selected so as to achieve specific acceptability standards rather than attempting to base them on the unknown value of marginal net damages' (p. 162) and 'In marked contrast to an attempt at optimisation, should iterative adjustments in tax rates prove desirable in a charges and standards approach, the necessary information would be easy to obtain. They require no data on costs or damages, only figures on current pollution levels' (p. 163). It is a 'least cost method for the achievement of these targets' (p. 164). The validity of the least cost theorem does not require profit maximisers or perfect competition, all that is necessary is that firms minimise cost for whatever output levels they select.

7. For example, as argued by IPCC (2014), despite the attractive properties of market-based instruments, their feasibility is potentially low because the cost of the emission reduction is more transparent than other climate policies. There is then a trade-off between feasibility and environmental effectiveness. Regulations that stimulate technology and behavioural change might be more costly (socially speaking), but more accepted by households and firms. Those trade-offs represent the usual clash between (long-run) social welfare and (short/long-run) welfare of societal parts.

8. We define in this paper three dimensions that cover a large extent of the 'feasibility' realm. We refer to Mitchell et al. (2011), Del Rio et al. (2012), IRENA (2014) and Bosetti and Frankel (2012) for discussions and treatment of the feasibility issue. As example, Del Rio (2009) framework is pretty similar in the treatment and coverage, since it includes effectiveness, cost effectiveness, dynamic efficiency and sociopolitical and legal feasibility. Equity is also included. We address equity concerns within sociopolitical feasibility, even though we are aware that equity more specifically pertains to access to resources (economic, technological), environmental distribution of effects and income distribution, which goes beyond unfeasibility intended as (excessive) costs on some part of societies, spatially, temporally and sectorally defined. Nevertheless, decreasing equity might increase the unfeasibility of implementing and achieving climate policy.

9. As example, Knopf et al. (2013) compares 13 models which estimate carbon prices that range from $€ 240$ per tonne $\mathrm{CO}_{2}$ to $€ 1127$ per tonne $\mathrm{CO}_{2}$ in 2050 . The median value is $€ 521$ per tonne $\mathrm{CO}_{2}$. The majority of studies find a sudden increase of carbon prices after 2040. The high carbon price required to reduce emissions questions the political feasibility of this scenario. Very recently, Paul Krugman has commented on the Paulson proposal for an extended emission tax by stressing that more socially costly measures (technology support to industry) might be used due to low social acceptability of environmental taxes.

10. Revenues per capita from UMTS auctions ranged from €20 per capita (Switzerland) to $€ 240$ per capita (Italy), up to €650 per capita (the UK). For an analysis of auction design and the impact it had on revenues in Italy and other countries see, among others, Klemperer (2002).

11. This is a relatively new instrument (from 2013) that envisages incentives for both private owners and public administrations that improve their buildings' energy efficiency. The incentives are given on the basis of well-detailed types of interventions, which need to be certified, and they are provided till the depletion of the annual budget. The interested reader can find additional information at http://www.gse.it/en/Heating_Cooling/Pages/default. aspx.

12. See, GSE reports on renewable energies for year 2011 at http://approfondimenti.gse.it/ approfondimenti/Simeri/fer/Pagine/default.aspx.

13. See, for example, EEA, EN35, 'External costs of electricity production': http://www.eea. europa.eu/data-and-maps/indicators/en35-external-costs-of-electricity-production/en35.

14. This information can again be derived from GSE reports on renewable energies for various years, available at: http://approfondimenti.gse.it/approfondimenti/Simeri/fer/Pagine/default. aspx.

15. http://www.eea.europa.eu/data-and-maps/indicators/renewable-primary-energy-consumption/ renewable-primary-energy-consumption-assessment-7 (last accessed, 7 February 2013). 
16. The new 'waste tariff' regime (called TIA) was introduced by Italian Law No. 22/1997, and substitutes for the former waste management tax (called TARSU). The transition, however, has been gradual, and the old tax has been in force in many municipalities until 2012 because law $22 / 1997$ provides for a transition phase that is quite slow. The tax was calculated on the size of household living spaces, while the tariff is based on principles of full-cost pricing for waste management services (Mazzanti et al. 2011).

17. Focusing on the EU electricity market, Thema et al. (2013) use a simulation model to assess the impact of the interactions between the EU-ETS and the EE-instruments on carbon price and emissions level. Similar estimations of the ETS-EE interactions are provided by Grubb (2012) and ÖkoInstitut (2012).

18. A full literature review is outside the scope of this paper. For a review of the relevant literature and problems (focused on the links between renewable electricity and emissions trading) see Del Rio (2007) and Philibert (2011). For a very recent and rather extensive review of the issues in the analysis of instruments interactions see, among others, Howlett and Del Rio (2013).

19. Namely, the efficiency society could get by equalising carbon abatement costs across countries and sectors through a unique carbon pricing. This efficiency outcome depends upon the existence of an EU-wide market and international agreement on $\mathrm{CO}_{2}$ targets, a pretty optimal 'state of the world' among others we might face and consider.

\section{References}

Aghion P, Veugelers R, Serre C. 2009. Cold start for the green innovation machine. Bruegel Policy Contribution; 2009/12. Brussels: Bruegel.

Arnell NW, Tompkins EL, Adger WN. 2005. Eliciting information from experts on the likelihood of rapid climate change. Risk Anal. 25:1419-1431.

Baumol WJ, Oates WE. 1988. The theory of environmental policy. Cambridge (UK): Cambridge University Press.

Borghesi S. 2011. The European emission trading scheme and renewable energy policies: credible targets for incredible results? Int J Sustainable Econ. 3(3):312-327.

Borghesi S, Cainelli G, Mazzanti M. 2012. European emission trading scheme and environmental innovation: an empirical analysis using CIS data for Italy. G Econ Ann Econ. 71(1):71-97.

Bosetti V, Frankel J. 2012. Sustainable cooperation in global climate policy: Specific formulas and emission targets. HKS Faculty Research Working Paper Series RWP12-012, John F. Kennedy School of Government, Harvard University.

Clò S. 2012. Apr. Certificati Bianchi: Funzionamento e Risultati Del Mercato Nazionale. Energia.

Convery F, Ellerman D, Kelly A. 2014 Jan. Future climate policies - challenges and choices: a European perspective. Dublin Workshop Synthesis.

D'Amato A, Mazzanti M, Montini A. 2013. Waste management in spatial environments. London: Routledge.

Del Rio P. 2007. The interaction between emissions trading and renewable electricity support schemes: an overview of the literature. Mitigation Adapt Strateg Glob Change. 12:1363-1390.

Del Rio P. 2009. Interactions between climate and energy policies: The case of Spain. Clim Policy. 9:119-138.

Del Rio P. 2010. Analysing the interactions between renewable energy promotion and energy efficiency support schemes: the impact of different instruments and design elements. Energy Policy. 38:4978-4989.

Del Rio P, Bleda M. 2013. Theoretical approaches to dynamic efficiency in policy contexts: the case of renewable electricity. In: Costantini V, Mazzanti M, editors. The dynamics of economic and environmental systems. London: Springer; p. 45-60.

Del Rio P, Ragwitz M, Steinhilber S, Resch G, Busch S, Klessmann C, de Lovinfosse I, Nysten Jana V, Fouquet D, Johnston A. 2012. Assessment criteria for identifying the main alternatives advantages and drawbacks, synergies and conflicts. A report compiled within the project beyond2020 (work package 2), supported by the EACI of the European Commission within the 'Intelligent Energy Europe' program Madrid (Spain): CSIC.

[DIW] Deutsches Institut für Wirtschaftsforschung. 2012. Die Auswirkungen des Atomausstiegs in Deutschland auf Strompreise und Klimaschutz in Deutschland und Europa. Studie im Auftrag von Greenpeace e.V. Berlin. 
[EC] European Commission. 2011a. Directive on energy efficiency and repealing Directives 2004/8/ EC and 2006/32/EC, COM(2011) 370. Brussels: European Commission.

EC. 2011b. Impact Assessment Accompanying the document Directive of the European Parliament and of the Council on energy efficiency and amending and subsequently repealing Directives 2004/8/EC and 2006/32/EC. Commission Staff Working Paper. Brussels: European Commission.

[EEA]. European Environment Agency. 2009. Diverting Waste from Landfill, EEA Report 7. Copenhagen: European Environment Agency.

EEA. 2010. Annual European Union greenhouse gas inventory 1990-2008 and inventory report 2010. Copenhagen (Denmark): European Environment Agency.

EEA. 2013a. Towards a green economy in Europe. Copenhagen: EEA.

EEA. 2013b. Trends and projections in Europe 2013. Copenhagen: EEA.

EEA. 2014. Resource efficient green economy and EU policies. Copenhagen: EEA.

Ellerman AD, Joskow PL. 2008. The European Union's emissions trading system in perspective. Arlington (VA): Pew Center on Global Climate Change.

[ETC/SCP] European Topic Center on Sustainable Consumption and Production. 2012. EU environmental and resource policies: strategic objectives and binding targets, version June 2012. Copenhagen: European Topic Center on Sustainable Consumption and Production.

ETC/SCP. 2013. Achieving a green economy in the EU through policy coherence and implementation. Copenhagen: European Topic Center on Sustainable Consumption and Production.

Fridolfsson SO, Tangerås T. 2012. A reexamination of Renewable Electricity Policy in Sweden. Stockholm: Research Institute of Industrial Economics (IFN). Working Paper No. 921.

Gilli M, Mazzanti M, Nicolli F. 2013. Sustainability and competitiveness in evolutionary perspective: Environmental innovation, structural change and economics dynamics in the EU. J Behav Exp Econ. 45:204-215.

Grubb M. 2012. Strengthening the EU-ETS. Creating a stable platform for EU energy investment. London: Climate Strategies.

Grubb M. 2014. Planetary economics: energy, climate change and the three domains of sustainable development. London: Routledge.

Hoffmann VH. 2007. EU ETS and investment decisions: the case of the German electricity industry. Europ Manag J. 25(6):464-474.

Howlett M, Del Rio P. 2013 Jun 28. Policy portfolios and their design: a meta-analysis. Paper presented at: 1st International Conference on Public Policy; Grenoble, France.

[IEA] International Energy Agency. 2011. Complementing carbon pricing with energy efficiency policy. Paris: International Energy Agency.

[IPCC] Intergovernmental Panel on Climate Change. Synthesis report on climate change 2007.

IPCC. 2014. Climate change 2014: mitigation of climate change. Working Group III Contribution to the IPCC 5th Assessment Report.

[IRENA] International Renewable Energy Agency. 2014. Evaluating renewable energy policy: a review of criteria and indicators for assessment. Abu Dhabi (UAE): IRENA.

[Istat] Italian National Institute of Statistics. 2012. La Tassazione ambientale in Italia - tavole (Environmental taxation in Italy - tables). Available from: www.istat.it Rome: Istat.

Klemperer P. 2002. How (not) to run auctions: the European 3G telecom auctions. Eur Econ Rev. 46:829-845.

Knopf B, Chen Y-HH, De Cian E, Förster H, Kanudia A, Karkatsouli I, Keppo I, Koljonen T, Schumacher K, van Vuuren DP. 2013. Beyond 2020—strategies and costs for transforming the European energy system. Clim Change Econ. 4(Suppl. 1):1-38.

Kolev A, Riess A. 2009. Europe's carbon emissions-trading scheme and its energy and industrial policy implications: heretical insights from basic economics. New York: MIMEO.

Lehmann P, Gawel E. 2013. Why should support schemes for renewable electricity complement the EU emissions trading scheme? Energy Policy. 52:597-607.

Marin G, Mazzanti M. 2013. The evolution of environmental and labour productivity dynamics. J Evol Econ. 23(2):357-399.

Mazzanti M, Montini A. 2014. Waste management beyond the Italian North-South divide: spatial analyses of geographical, economic and institutional dimensions. In: Kinnaman TC Takeuchi K, editors. Handbook on waste management. Cheltenham (UK): Edward Elgar. 
Mazzanti M, Montini A, Nicolli F. 2011. Embedding landfill diversion in economic, geographical and policy settings. Appl Econ. 43:3299-3311.

Mazzanti M, Zoboli R. 2006. Economic instruments and induced innovation: the European policies on end-of-life vehicles. Ecol Econ. 58(2):318-337.

Mazzanti M, Zoboli R. 2013. Jul. Resource taxation and regional planning. J Environ Plan Manag. 56(6):893-916.

Mitchell C, Sawin JL, Pokharel GR, Kammen D, Wang Z, Fifita S, Jaccard M, Langniss O, Lucas H, Nadai A, et al. 2011. Policy, financing and implementation. IPCC special report on renewable energy sources and climate change mitigation. Cambridge (UK): Cambridge University Press. Available from: http://srren.ipcc-wg3.de/report/IPCC_SRREN_Ch11.pdf

Morgan MG, Keith DW. 1995. Subjective judgments by climate experts. Environ Policy Anal. 29:468-476.

Mundaca L. 2007. Transaction costs of Tradable White Certificate schemes: the Energy Efficiency Commitment as case study. Energy Policy. 35(8):4340-4354.

Napp TA, Gambhir A, Hills TP, Florin N, Fennell PS. 2014 Feb. A review of the technologies, economics and policy instruments for decarbonising energy-intensive manufacturing industries. Renew Sust Energ Rev. 30:616-640.

Nicolli F, Mazzanti M. 2013. Landfill diversion in a decentralized setting: a dynamic assessment of landfill tax. Resour Conserv Recy. 81:17-23.

Nordhaus WD. 1994. Expert opinion on climate change. Am Sci. 82:45-51.

OECD. 2013. Environmental performance review: Italy. Paris: Organization for Economic Cooperation and Development.

ÖkoInstitut. 2012. Strengthening the European Union Emission Trading Scheme and raising climate ambition. Freiburg (Germany): ÖkoInstitut, WWF and Greenpeace.

Pearson A. 2010. The carbon rich list: the companies profiting from the EU Emissions Trading Scheme. London (UK): Sandbag Climate Campaign.

Philibert C. 2011. Mar. Interactions of policies for renewable energy and climate. IEA Energy Paper. Available from: http://econpapers.repec.org/paper/oecieaaaa/2011_2f6-en.htm Paris: OECD.

Pontoglio S. 2010. An early assessment of the influence on eco-innovation of the EU Emissions Trading Scheme - evidence from the Italian paper industry. In: Mazzanti M, Montini A, editors. Environmental efficiency, innovation and economic performance. London: Routledge.

Rogge K, Schneider M, Hoffmann V. 2011. The innovation impact of the EU Emission Trading System - findings of company case studies in the German power sector. Ecol Econ. 70:513-523.

Schmidt TS, Schneider M, Rogge KS, Schuetz MJA, Hoffmann VH. 2012. The effects of climate policy on the rate and direction of innovation: a survey of the EU ETS and the electricity sector. Environ Innov Soc Trans. 2:23-48.

Sorrell S, Harrison D, Radov D, Klevnas P, Foss A. 2009. White certificate schemes: economic analysis and interactions with the EU ETS. Energy Policy. 37:29-42.

Thema J, Suerkemper F, Grave K, Amelung A. 2013. The impact of electricity demand reduction policies on the EU-ETS: modelling electricity and carbon prices and the effect on industrial competitiveness. Energy Policy. 60:656-666.

Varho V, Tapio P. 2013. Combining the qualitative and the quantitavive with the Q2 scenario technique - The case of transport and climate. Technol Forecast Soc Change. 80(4):611-630.

Zubaryeva A, Thiel C, Barbone E, Mercier A. 2012. Assessing factors for the identification of potential lead markets for electrified vehicles in Europe: expert opinion elicitation. Technol Forecast Soc Change. 79:1622-1637. 